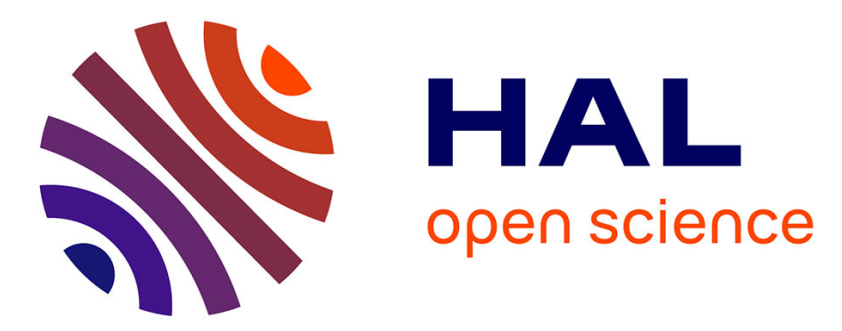

\title{
Seismic Activity Preceding the 2011 M w 9.0 Tohoku Earthquake, Japan, Analyzed With Multidimensional Template Matching
}

B. Gardonio, Michel Campillo, D. Marsan, A. Lecointre, M. Bouchon, J. Letort

\section{To cite this version:}

B. Gardonio, Michel Campillo, D. Marsan, A. Lecointre, M. Bouchon, et al.. Seismic Activity Preceding the 2011 M w 9.0 Tohoku Earthquake, Japan, Analyzed With Multidimensional Template Matching. Journal of Geophysical Research: Solid Earth, 2019, 124 (7), pp.6815-6831. 10.1029/2018jb016751 . hal-02928090

\section{HAL Id: hal-02928090 https://hal.univ-grenoble-alpes.fr/hal-02928090}

Submitted on 2 Sep 2020

HAL is a multi-disciplinary open access archive for the deposit and dissemination of scientific research documents, whether they are published or not. The documents may come from teaching and research institutions in France or abroad, or from public or private research centers.
L'archive ouverte pluridisciplinaire HAL, est destinée au dépôt et à la diffusion de documents scientifiques de niveau recherche, publiés ou non, émanant des établissements d'enseignement et de recherche français ou étrangers, des laboratoires publics ou privés. 


\section{JGR Solid Earth}

\author{
RESEARCH ARTICLE \\ 10.1029/2018JB016751 \\ Key Points: \\ - We developed a multidimensional \\ template matching technique to \\ detect small seismic events \\ - Events detected at low frequency \\ $(1-10 \mathrm{~Hz})$ see the migration episode \\ before the Tohoku event and are \\ located in potential creeping zones \\ - The rate of events detected at high \\ frequency $(>14 \mathrm{~Hz}$ ) increases from \\ November 2010 to the Tohoku \\ earthquake
}

Supporting Information: - Supporting Information S1 - Table S1

- Table S2

Correspondence to:

B. Gardonio,

gardonio@geologie.ens.fr

Citation:

Gardonio, B., Campillo, M. Marsan, D., Lecointre, A., Bouchon, M., \& Letort, J. (2019). Seismic activity preceding the 2011 $M w 9.0$ Tohoku earthquake, Japan, analyzed with multidimensional template matching (MDTM). Journal of Geophysical Research: Solid Earth, 124. https://doi.org/10.1029/ 2018JB016751

Received 25 SEP 2018 Accepted 27 MAY 2019 Accepted article online 2 JUN 2019

(C)2019. American Geophysical Union. All Rights Reserved.

\section{Seismic Activity Preceding the 2011 Mw9.0 Tohoku Earthquake, Japan, Analyzed With Multidimensional Template Matching}

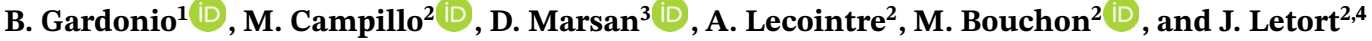 \\ ${ }^{1}$ Laboratoire de Géologie, Département de Géosciences, École Normale Supérieure, CNRS UMR 8538, PSL Research \\ University, Paris, France, ${ }^{2}$ Université Grenoble Alpes, Université Savoie Mont Blanc, CNRS, IRD, IFSTTAR, ISTerre, \\ Grenoble, France, ${ }^{3}$ Université Grenoble Alpes, Université Savoie Mont Blanc, CNRS, IRD, IFSTTAR, ISTerre, \\ Chambéry, France, ${ }^{4}$ Institut d'Astrophysique et de Planétologie (IRAP), CNRS/UPS, Toulouse, France
}

\section{Introduction}

The displacements of inland GPS stations before the Tohoku earthquake show a decrease of slip deficit rate, hence of coupling, between 1998 and 2011 downdip the coseismic rupture zone of the megathrust earthquake (Mavrommatis et al., 2014; Yokota \& Koketsu, 2015). This indicates the existence of a long-term and large-scale deformation transient before the Tohoku earthquake. This is confirmed by the analysis of the declustered seismicity in the downdip area of the epicentral Tohoku earthquake (Marsan et al., 2017).

The preseismic phase in the epicentral region of the megathrust earthquake becomes visible in the seismicity in mid-January 2011. It is coincident with an increase of deep (>80 km) seismicity (Bouchon et al., 2016; see Delbridge et al., 2017, for a different conclusion on this). The preseismic phase gave birth to bursts of seismicity starting on mid-February, lasting for about 23 days (Hirose et al., 2011). Two days before the mainshock, a Mw7.3 foreshock struck close to the initiation point of the Tohoku earthquake. The seismicity between this largest foreshock and the mainshock includes several $M \geq 6$ earthquakes and appears to migrate toward the mainshock epicenter, suggesting the presence of afterslip (Ando \& Imanishi, 2011) and/or interaction mechanisms between earthquakes (Marsan \& Enescu, 2012). Two distinct sequences of slow-slip transients propagating toward the rupture initiation point were evidenced by the detection of Repeating Earthquakes (ie earthquakes with highly similar waveforms and which rupture overlap, at least partially) (Kato et al., 2012).

Several methods have been developed in the past to detect and localize small events using matching phase signals on an array (Gibbons \& Ringdal, 2006; Got et al., 1994; Rost \& Thomas, 2002). In earthquake detection, the technique of cross-correlation between seismic events has been widely used to detect Repeating Earthquakes (Kimura et al., 2006; Matsuzawa et al., 2002; Nadeau \& McEvilly, 1997; Uchida et al., 2003). The waveform matching technique was also successful in detecting low frequency earthquakes (LFE) and 
non-volcanic tremors (NVT), (Aso et al., 2011; Shelly et al., 2007) as well as detecting missing earthquakes during foreshock (Bouchon et al., 2011; Kato et al., 2012) or aftershock sequences of large earthquakes (Lengliné \& Marsan, 2009; Lengliné et al., 2012; Peng \& Zhao, 2009).

Analysis of the seismicity during the preseismic phase of the Tohoku earthquake have been done before with classical detection techniques (Kato et al., 2012; Uchida \& Matsuzawa, 2013) or by using ocean-bottom pressure gauges (Ito et al., 2013). The density of the Japanese seismic network of continuous and broad-frequency range stations offers a unique opportunity to apply an improved detection technique before the Tohoku earthquake that allows to detect seismic events well below the noise level.

This technique has been first introduced by Mermoz (1976) and used in underwater acoustic (Bienvenu \& Kopp, 1983; Turek \& Kuperman, 1997; Jensen et al., 2011) and seismic exploration (Glangeaud \& Lacoume, 1985; Glangeaud \& Latombe, 1986; Samson, 1983). This method considers the network as an array of receivers instead of using the classical station by station approach. We use all the $M \geq 2$ earthquakes that occurred from mid-February 2011 to the time of the megathrust earthquake as template events, and we search for their matches in the continuous signal from 1 January 2011 to 11 March 2011 to analyze their temporal distribution.

\section{Data and Methods}

\subsection{Method}

The method presented here is a multidimensional template matching (MDTM) technique. The algorithm is implemented in the frequency domain and is presented in Figure 1. The aim of the method is to detect small earthquakes that are similar to templates. Seismic records at stations that belong to a network share a coherent signal. Thus, the coherent pattern that defines a template can be used to search for smaller earthquakes that share this coherent signal, following the method described hereafter.

A template is composed by signals $d_{j}(t)$ recorded in the time domain (Figure 1 on the left). We first roughly align the traces in order to have all the $P$ wave arrival times at the beginning of the window. To do so, we estimate the time of arrival at each station using a $P$ wave velocity of $6.8 \mathrm{~km} / \mathrm{s}$. Precision is not necessary here since we only need the information about the coherent signal that we want to retrieve in the continuous signal (so all the $P$ waves in the window). We normalize the traces by their maximum and compute the Fourier transform of the signals for the $N$ stations: $d(\omega)=\left[d_{1}(\omega), \ldots, d_{N}(\omega)\right]$, with $d_{j}(\omega)=F T\left[d_{j}(t)\right]$ organized in column (i.e., $d$ is a column vector) and calculate the cross-spectral density matrix (CSDM), $K$ (i.e., a $N \times N$ matrix) as

$$
K(\omega)=d(\omega) d^{*}(\omega)
$$

where $*$ indicates the Hermitian transpose operation (Figure 1, step 1).

The information that we wish to retrieve in the continuous signal is the phase pattern of the signals for the network (this is why we did not apply perfect moveouts). Furthermore, we search for signals that contain balistic waves and are thus coherent between stations.

The next step consists in decomposing the matrix $K$ in eigenvalues and eigenvectors (Figure 1, step 2). Since the matrix $K$ is squared and hermitian, an eigen decomposition or a singular value decomposition gives the same results. Here, we use the eigen decomposition as follows:

$$
K(\omega) v=\lambda v .
$$

This allows to decompose the CSDM as an ensemble of eigenvectors $v$ and eigenvalues $\lambda$ that we sort in descending order.

The continuous signal is composed by signals $D_{j}(t)$ recorded in the time domain (Figure 1 on the top right). We apply the same normalization and moveout on the continuous signal as we did for the template events using a $P$ wave velocity of $6.8 \mathrm{~km} / \mathrm{s}$. Using the first eigenvector $\left(v_{1}\right)$ that contains the most energetic and coherent signal, we can define a new trace that is a projection of the continuous signal $D$ on the first eigenvector at every frequency (Figure 1, step 3)

$$
Z(\omega)=v_{1}^{*} D(\omega) v_{1} .
$$

where $D_{j}(\omega)=F T\left[D_{j}(t)\right]$. At this stage, we obtain $N$ signals $Z_{j}(t)$ in time, one per station $j$, as the inverse FT of $Z_{j}(\omega)$. Normalization is necessary because it prevents strong signal recorded at one station to dominate the 


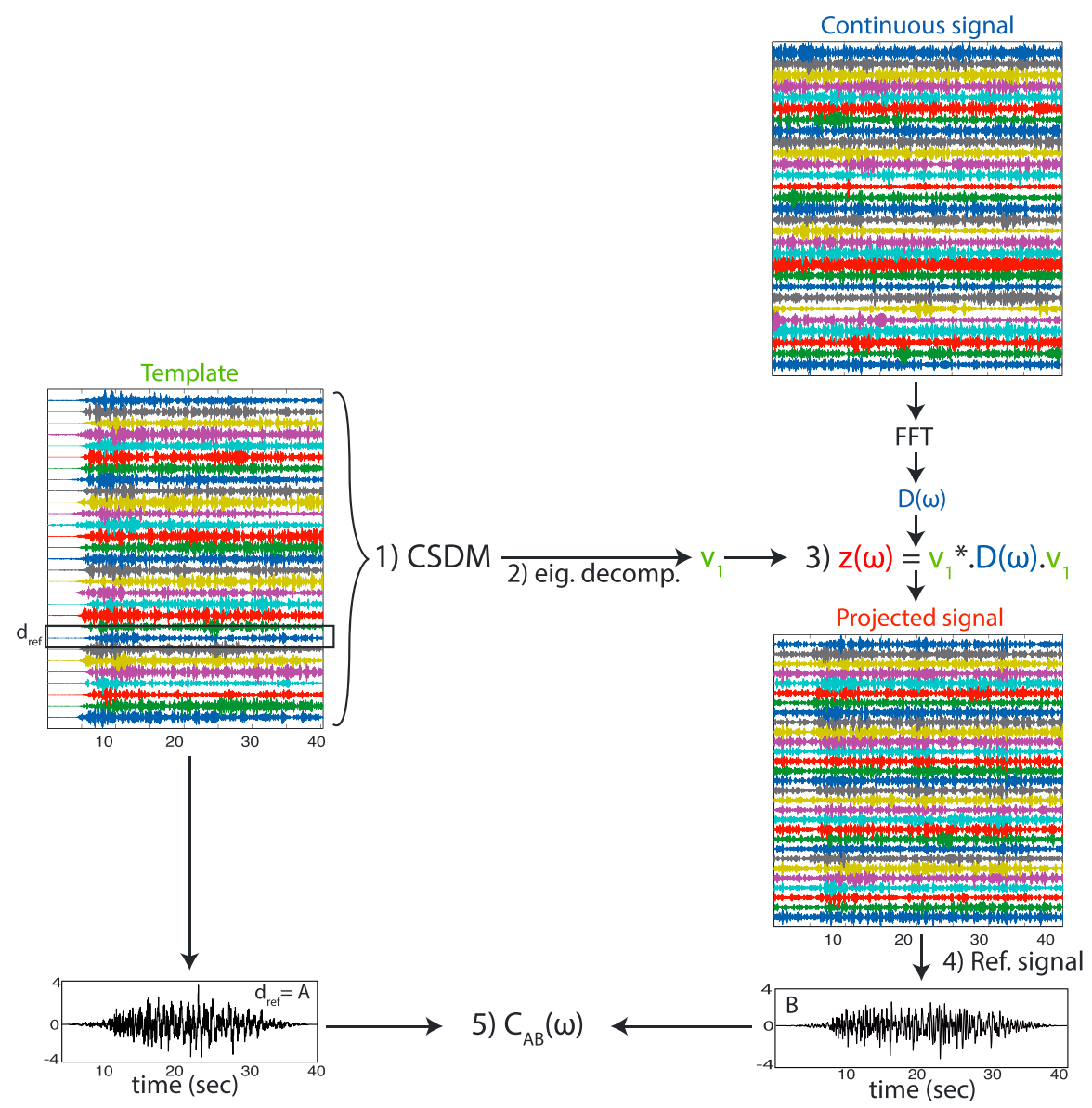

Figure 1. Description of the stages used in the multidimensional template matching algorithm. (1) CSDM calculation, (2) eigen decomposition, (3) projection on the continuous signal using the first eigen vector, (4) definition of the reference signal, and (5) coherency calculation. The template occurred on 10 March 2011 at $8 \mathrm{hr} 36 \mathrm{~min} 56 \mathrm{~s}$ (magnitude 5.2) and the detection occurred on 10 February 2011 at 23hr50min30s. CSDM = cross-spectral density matrix.

projection. Once the projected signal is defined, we can easily work in the time domain in order to compare the template and the output (Figure 1, bottom right). To do so, we define a reference signal for the template on the one hand and for the output of the projection on the other hand (Figure 1, step 4) by propagating the signal recorded at station $j$ to one reference station.

Defining a reference signal prevents from calculating the coherency station by station and has the advantage of keeping all the information contained in the output projected signal. The reference station is the one with the highest signal-to-noise ratio among the first 10 arrival stations. We define the propagator as

$$
G_{j}(\omega)=\frac{d_{\text {ref }}(\omega)}{d_{j}(\omega)}
$$

with $d_{\text {ref }}(\omega)$ the Fourier transform of the signal recorded at the reference station and $d_{j}(\omega)$ the Fourier transform of the signal recorded at station $j$.

Finally, we obtain a reference signal $A$ for the template

$$
A=d_{\text {ref }}(t)
$$

We perform the propagation (equation (6)) and sum (equation (7)) for the projected signals $Z_{j}(\omega)$ using the very same propagator $G_{j}(\omega)$, to obtain $B$

$$
Z_{\text {ref }}^{(j)}(\omega)=Z_{j}(\omega) G_{j}(\omega)
$$



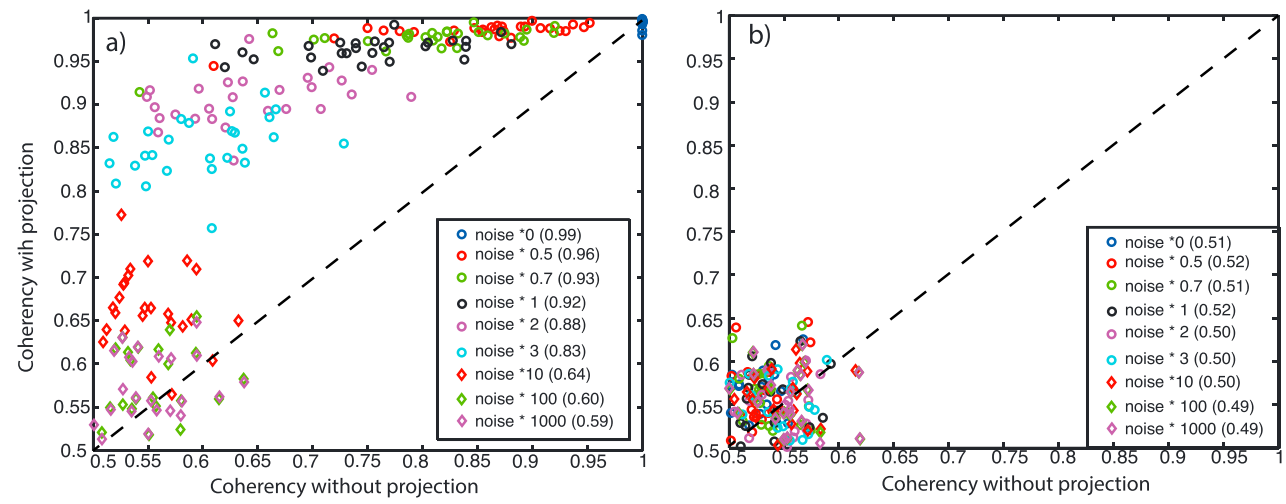

Figure 2. Comparison of the coherency calculated at every station used in this study, with and without projection. The level of noise is given in the legend (e.g., noise $* 2$ means a noise level that has 2 times the amplitude of the signal). The coherency between the two reference signals for the projection method is given in brackets for every noise level. The dashed line has a slope of 1. (a) For an autodetection: the noise is added to the original data and we calculate the coherency between the original and the noisy signal. (b) The noise is added to a random earthquake signal that bears no similarity with the template.

$$
B(t)=\frac{1}{N} \sum_{j=1}^{N} Z_{\mathrm{ref}}^{(j)}(t),
$$

which can be compared to $A$.

The last stage of the detection algorithm consists in calculating the coherency between A and B (Figure 1, step 5) over their 20 first seconds, which correspond to the arrival and coda of the $P$ wave, as

$$
C_{A B}(\omega)=\frac{\overline{A(\omega) B^{*}(\omega)}}{\sqrt{\overline{A(\omega) A^{*}(\omega)}} \sqrt{\overline{B(\omega) B^{*}(\omega)}}} .
$$

The coherency is calculated between two frequencies, $f 1$ and $f 2$, with $f 2=f 1+\Delta f$ and $\Delta f=5 \mathrm{~Hz}$ minimum. Thus, $f 1$ ranges from 1 to $15 \mathrm{~Hz}$ and $f 2$ from 5 to $20 \mathrm{~Hz}$ (i.e., the frequency band of interest spans from 1 to $20 \mathrm{~Hz}$ ). We keep only the maximum value of coherency from all the calculated frequency bands.

We compare this detection method with the simple calculation of the coherency station by station. To do so, we add a certain level of noise to the original data and calculate the coherency between 1 and $8 \mathrm{~Hz}$, station by station, between the original and the noisy signals with or without projection (Figure 2). The signals are normalized, and the noise standard deviation is $n$ times the standard deviation of the signal. We first compare the two detection methods for an autodetection, that is, a template that detects itself, (cf. Figure 2a) and see that without any noise in the signal, the coherency without projection is equal to 1 . Due to the fact that the projected signal is a linear combination between stations, the coherency is slightly lower with the projected signal. With the MDTM, it is still possible to obtain a high coherency value (above 0.9) with noise up to 2 times the amplitude of the signal which is not the case without the projection. This shows the robustness of this projection technique. We also test the results with two different signals that do not show any similarity and see that the coherency is always low regardless of the noise level (cf. Figure 2b): the projection thus does not create artificially high coherency values when the continuous signal does not bare any similarity with the template. Furthermore, we compare the "classical" template matching technique and the MDTM technique with 10 templates (Figure S3 in the supporting information). The MDTM is more powerful than the classical method.

\subsection{Data}

The preseismic phase of the Tohoku earthquake seems to start in mid-January coincidently with an outburst of deep seismicity (Bouchon et al., 2016). The preseismic phase went on with bursts of seismicity in mid-February that lasted about 23 days (Hirose et al., 2011). Two days before the mainshock, a Mw7.3 foreshock struck close to the initiation point of the Tohoku earthquake (Figure 3). The postseismic slip of this foreshock is mainly located between the two epicenters (Ohta et al., 2012). Furthermore, its aftershocks were mostly located north to the Tohoku earthquake epicenter (Figure $3 b$ ). 


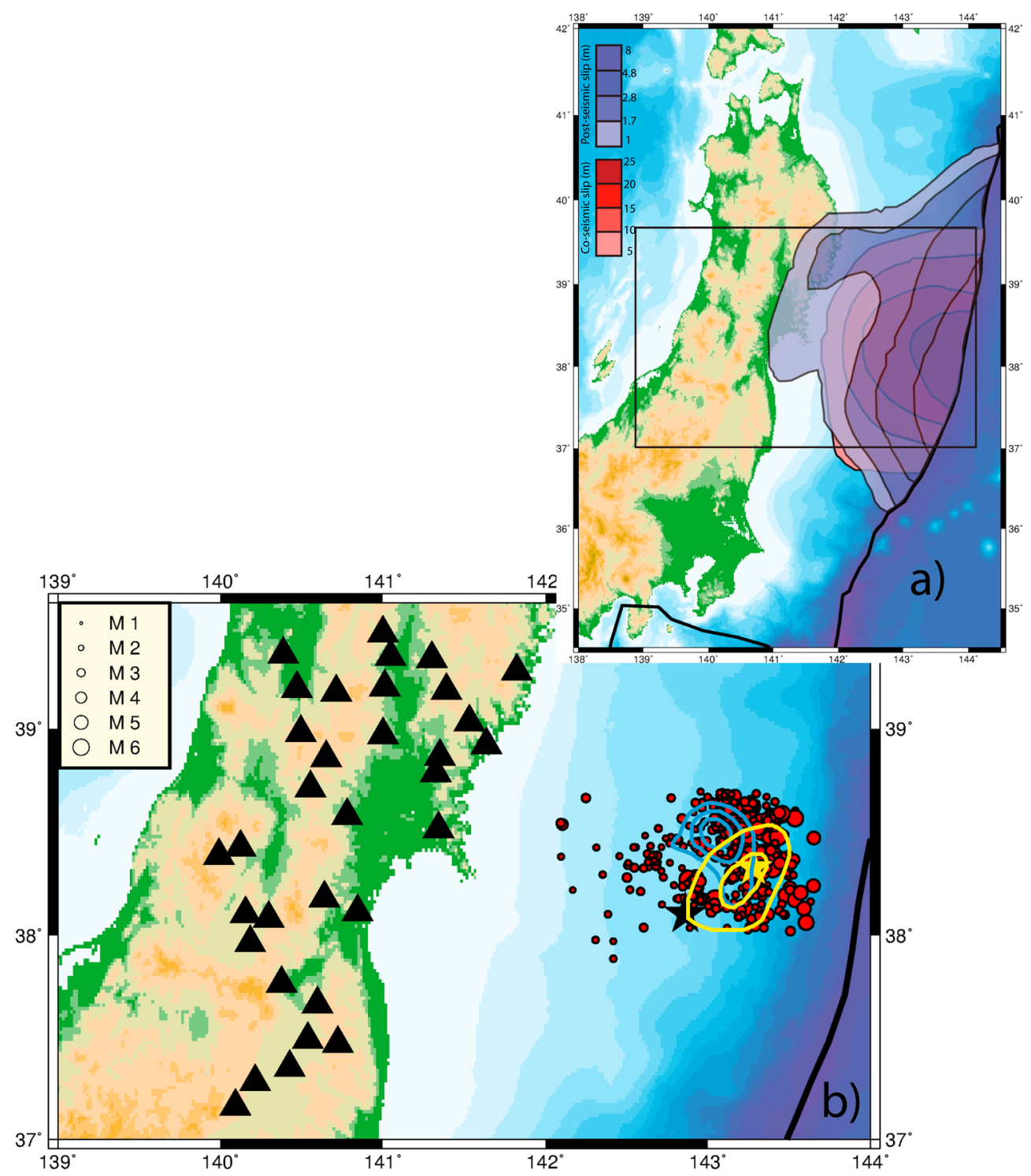

Figure 3. Map of the region of the 2011 Tohoku-Oki earthquake. (a) Coseismic (red) and postseismic (blue) slip distribution of the Tohoku eartquake estimated using both GEONET GPS stations and six near trench stations that include coseismic slip and 21 days of postseismic slip (modified from Perfettini \& Avouac, 2014). (b) Location of the templates (red circles) and of the Hi-net stations (black triangles) used in this study. The black and yellow stars locate the epicenter of the Tohoku earthquake and its $M w 7.3$ foreshock. Estimated coseismic and postseismic slip distribution of the $M w 7.3$ foreshock are given with blue and yellow contours drawn at, respectively, every 0.5- and 0.1-m interval with a maximum of 1.5 and $0.4 \mathrm{~m}$ (Ohta et al., 2012).

In order to apply the MDTM technique, we use all the $498 M \geq 2$ earthquakes that occurred from 13 February 2011, time of the beginning of the study by Kato et al. (2012), to 11 March 2011, in the Japan Meteorological Agency (JMA) catalog, as template events.

Using the technique presented above, we search for resembling signals in the vertical component of continuous signals of $33 \mathrm{Hi}$-net stations located in Tohoku region (Figure 3). The sampling frequency of these stations is $100 \mathrm{~Hz}$. We analyzed the continuous signal from 1 January 2011 to 12 March 2011 in order to observe the potential activation of the area around mid-January.

The projection of the CSDM is done for every template over the gap filled continuous signal on a sliding window that is 4,096 samples long (40.96 s) and that slides every 512 samples ( $5.12 \mathrm{~s}$ ). We finally filter out duplicate detections of the same event that were detected by several templates by taking the maximum coherency value in every 40-s-long windows. An example of a detection is given in Figure 4 . The detection is 

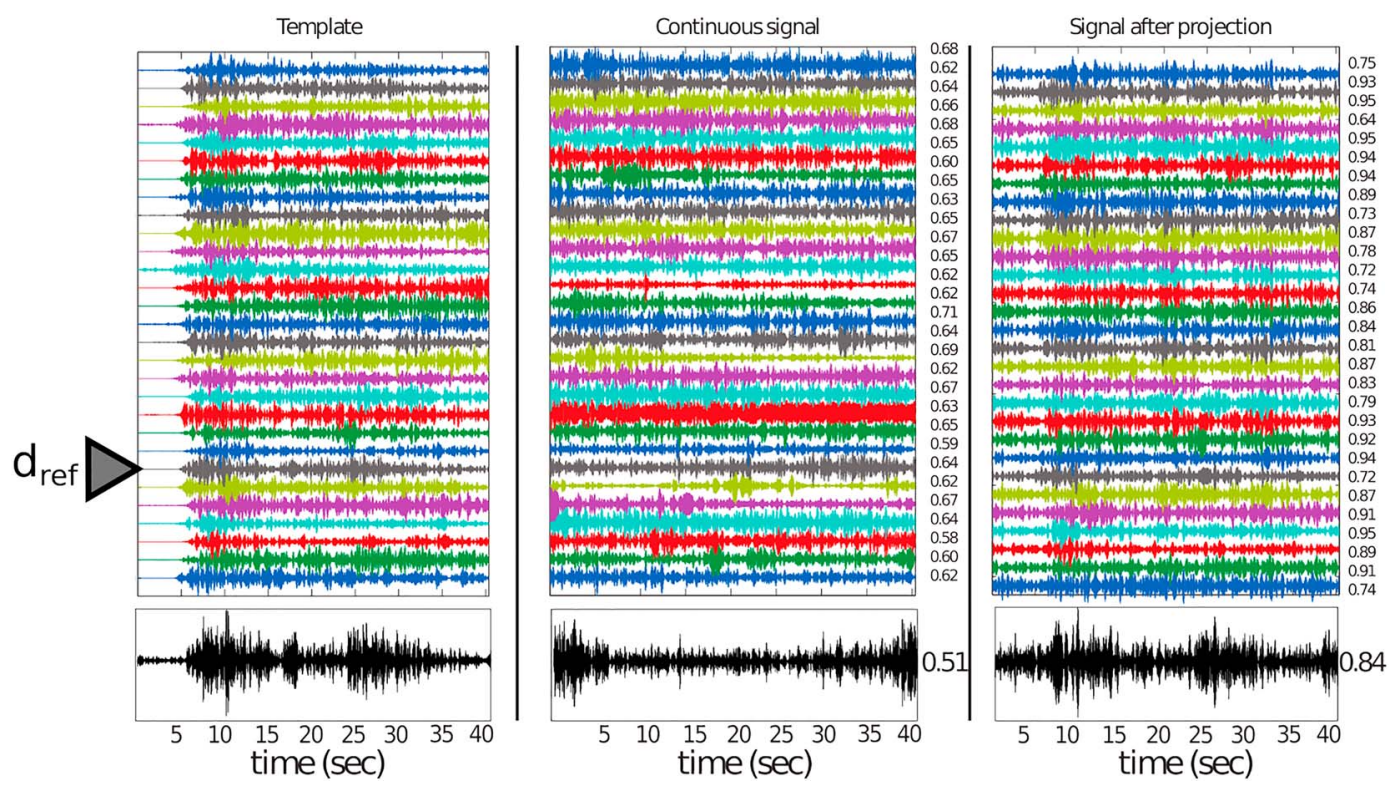

Figure 4. Example of a detection at high frequencies (between 14 and $20 \mathrm{~Hz}$ ). The template occurred on $10 \mathrm{March}$ 2011 at $8 \mathrm{hr} 36 \mathrm{~min} 56 \mathrm{~s}$ (magnitude 5.2). Its signal recorded at every station is shown on the left. We project the first eigen vector of the cross-spectral density matrix of the template over the continuous signal that is shown in the middle, obtaining the projected signal (on the right) which gives a detection that occurred on 10 February 2011 at $23 \mathrm{hr} 50 \mathrm{~min} 30 \mathrm{~s}$. The coherency values between the input signal on the one hand and the continuous and projected signals on the other hand are shown on the right of every trace. The black signals at the bottom show the normalized reference signals (here the station N.KAKH was used as $d_{\text {ref }}$ ), and the coherency values between the reference signals are indicated on the right.

highest at high frequencies, between 14 and $20 \mathrm{~Hz}$ for this example. The algorithm allows to mainly detect the $P$ wave arrival which corresponds to the most energetic phase at high frequencies (Figure 4 on the right).

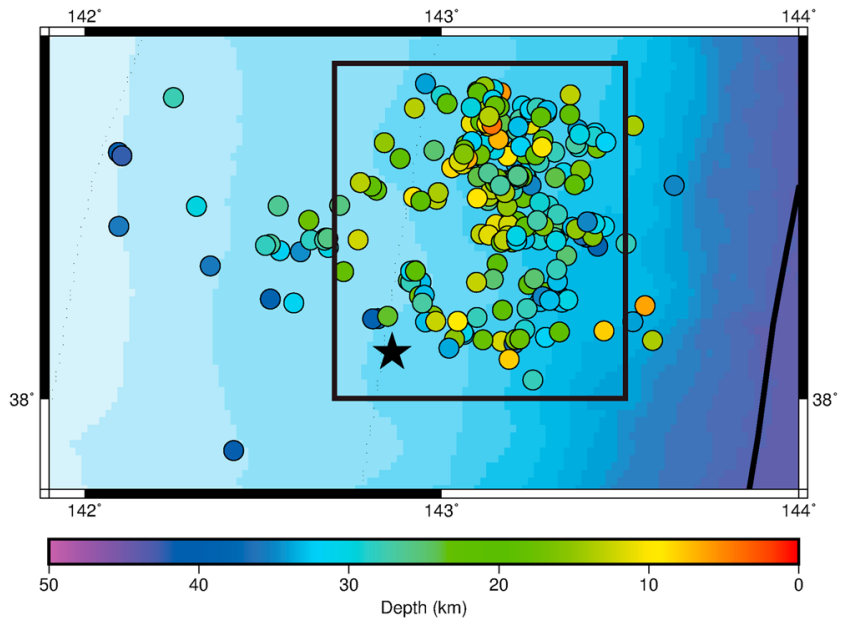

Figure 5. Locations of the templates that have at least one detection, other than their autodetection, color coded according to their depths. The black rectangle shows the area studied in Figure 6.

\section{Results}

\subsection{Earthquake Detection}

From 1 January 2011 to 12 March 2011, the JMA catalog counts 921 earthquakes with a magnitude $\geq 0$ including the 498 templates that we used. Two hundred one events already listed in the JMA were detected with our method (so these earthquakes have a magnitude comprised between 0 and 2), and the rest is too far away (more than $70 \mathrm{~km}$ on average) from the templates to be detected (see Figures S1 and S2 of the supporting information). By using the MDTM algorithm and a coherency threshold of 0.8 , we detect 395 new events. When lowering the coherency threshold to 0.7 , we obtain 2,360 events. Going down to such threshold would imply a strong defocusing of the method (i.e., we would potentially detect earthquakes that are far from the targeted area). We here decide to raise the threshold to make sure that the detections were indeed meaningful.

The preseismic phase of the Tohoku earthquake began in mid-January with burst-like seismicity in the studied area defined by the black rectangle in Figure 5 that can barely be seen in the JMA catalog (Figure 6).

It triggered 19 new events and lasted $30 \mathrm{hr}$. This coincides with a sudden increase of activity at depth (Bouchon et al., 2016). The seismic activity is then rather constant until the second burst that occurred from 13 February 2011 to 16 February 2011 when 37 new earthquakes occurred over $72 \mathrm{hr}$. After this burst, the seismic activity is 10 times higher than the 


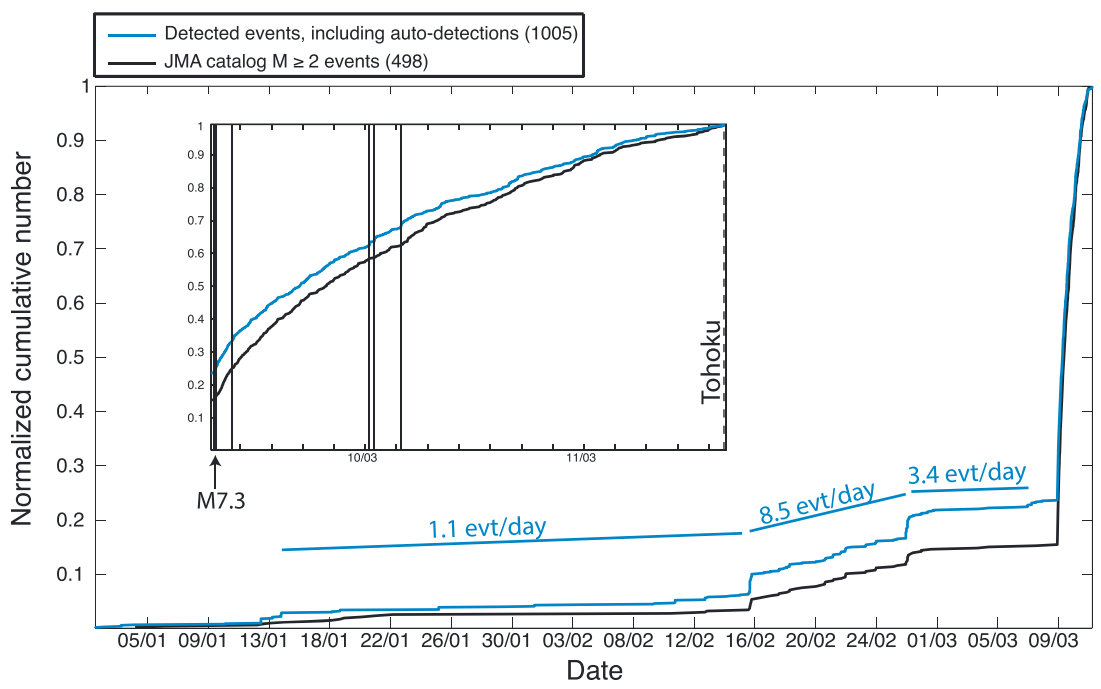

Figure 6. Normalized cumulative number of all earthquakes that are detected with templates located in the black rectangle of Figure 5. In blue: all detected events (including the auto-detections); in black: all the $M \geq 2$ earthquakes in the JMA catalog. The total numbers are given in bracket in the legend. Inset: zoom on the period after the $M w 7.3$ foreshock. The black lines indicate the time of occurrence of $M \geq 6$ earthquakes, and the dashed line indicates the Tohoku earthquake. JMA = Japan Meteorological Agency.

previous seismic rate until 26 February 2011 when a third burst similar to the previous one occurs. It also triggers 37 new events over $73 \mathrm{hr}$. After this burst, the activity is almost back to its normal rate and increases one more time during a seismic burst on 7 March 2011 that lasts $24 \mathrm{hr}$ and triggers 14 new earthquakes. After this smaller burst, a quiescence settles until the $M w 7.3$ foreshock rupture.

Large magnitude templates ( $M 5$ and M6) detect as many times as small magnitudes (M2) even if the distribution of the template magnitudes seems to follow a classical Gutenberg-Richter law (Figure 7).

Furthermore, the $M 2$ to $M 4$ templates mainly detect events within a low-frequency band, with a mean $f 1$ at $3 \mathrm{~Hz}$ (Figure 8). On the contrary, large magnitude templates detect at high frequencies ( $f 1$ between 10 and $15 \mathrm{~Hz}$ ). There is also a remarkable gap between these two end-members where only a few detections are found. The corner frequency of a $M=2$ event being less than $20 \mathrm{~Hz}$, it is not surprising to detect at low frequencies for small earthquakes. At high frequencies, the detection are based on high signal-to-noise ratio templates corresponding to high-amplitude and high-frequency radiation from large earthquakes. In that case, the duration of the event is far much larger than one of the detected events and the detection with CSDM projection fully relies on the signature of the propagation of a high-frequency wave, for a given
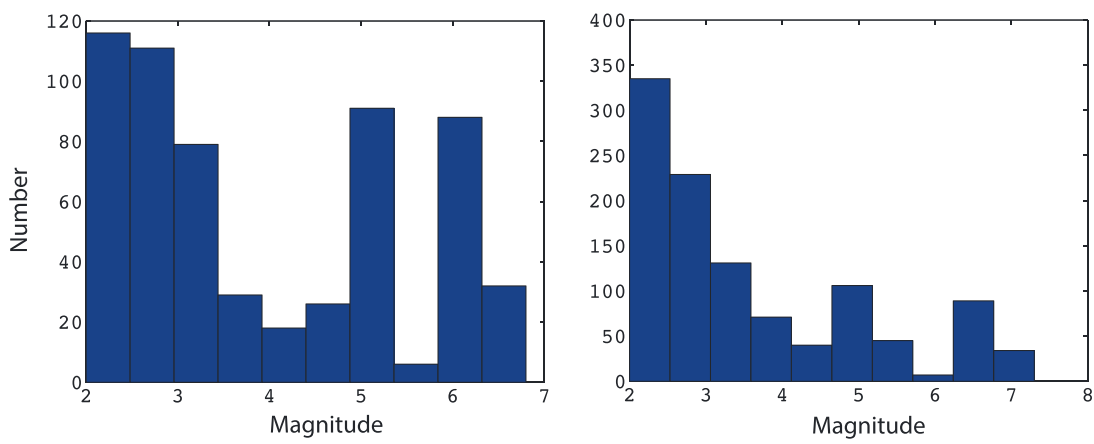

Figure 7. (left) Number of detections according to the template magnitude. (right) Number of templates according to their magnitude. 


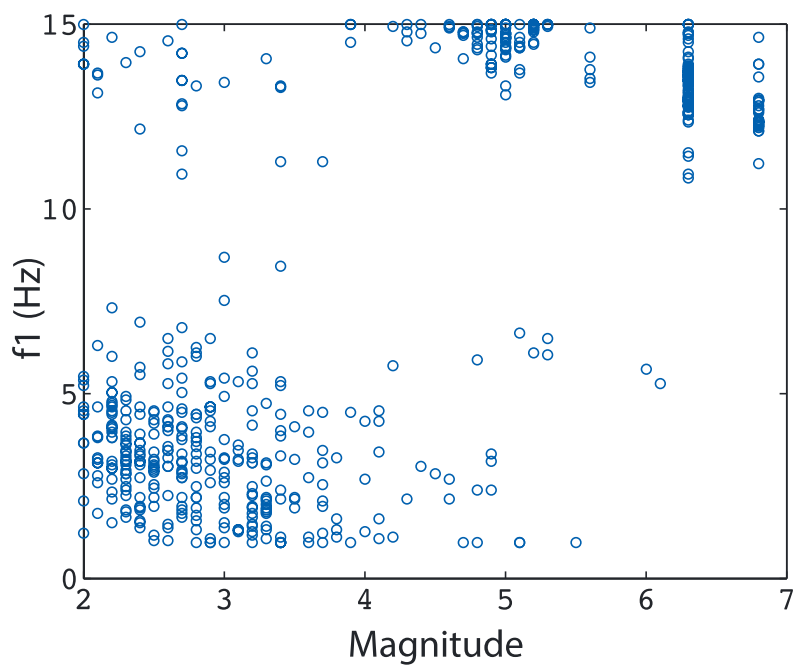

Figure 8. Lower frequency (f1) for the frequency window used in the coherency calculation $(\mathrm{Hz})$ versus the template magnitudes. Note that autodetections are not shown here. frequency band and not a direct match of waveform. Largest templates provide high-quality high-frequency CSDM to be used for detection.

\subsection{Spatial Resolution and Coherency Threshold}

By using the MDTM algorithm, it is possible to detect small earthquakes hidden in low signal-to-noise ratio signals. However, the technique is based on the analysis of the CSDM and on a linear decomposition. As previously mentioned, normalization is necessary to give equal weight to all signals. Therefore, the absolute time and the real signal amplitudes are not available after projection preventing us to obtain the precise time of occurrence or the magnitude. Since the window of analysis slides over $5 \mathrm{~s}$, we do know that the detected events occurred during this time lapse and the use of the continuous signal to locate the detected earthquakes could be a solution; however, it is highly noisy for most of the detections (Figure 4, middle) preventing us from calculating a time delay.

Locating earthquakes detected by template matching technique is uncommon, and only a few studies have done it (Shelly et al., 2016; Zhang \& Wen, 2015). However, we propose here a way to assess the spatial resolution of the MDTM technique.

To better constrain the distribution of the distance, we compute the coherency and the distance for every pair of templates without taking into account the autodetections. We calculate the hypocentral distances using the hypocenter solutions of the JMA catalog. We separated the pairs of templates that present a maximum coherency value at low frequency (i.e., $1 \leq f 1 \leq 5 \mathrm{~Hz}$; Figure 9, red dots) and at high frequencies $(f 1 \geq$ $10 \mathrm{~Hz}$; Figure 9, green dots).

For templates that have a maximum coherency value at low frequency, it is clearly visible that the distribution begins to be more concentrated to small distances for coherencies above 0.8 . The dispersion is larger above the threshold of 0.8 for pairs of templates that have their maximum coherency value at high frequency.

Furthermore, $84 \%$ of the pairs of templates that have their maximum coherency value at low frequency are located below $22.6 \mathrm{~km}$ for the 0.8 threshold and below $15.6 \mathrm{~km}$ for coherencies between 0.9 and 1 (Figure 10). The trend is similar when considering $84 \%$ or $95 \%$ of the pairs: the distance suddenly increases for values of coherencies smaller than 0.8 .

For a coherency threshold of $0.8,84 \%$ of the pairs of templates that have their maximum coherency value at high frequency $(f 1>=10 \mathrm{~Hz})$ have a maximum distance of $49 \mathrm{~km}$. In this case, only 28 pairs are considered which might not be statistically significant. However, the resolution seems stronger for pairs of templates that have their maximum coherency value at low frequency than at high

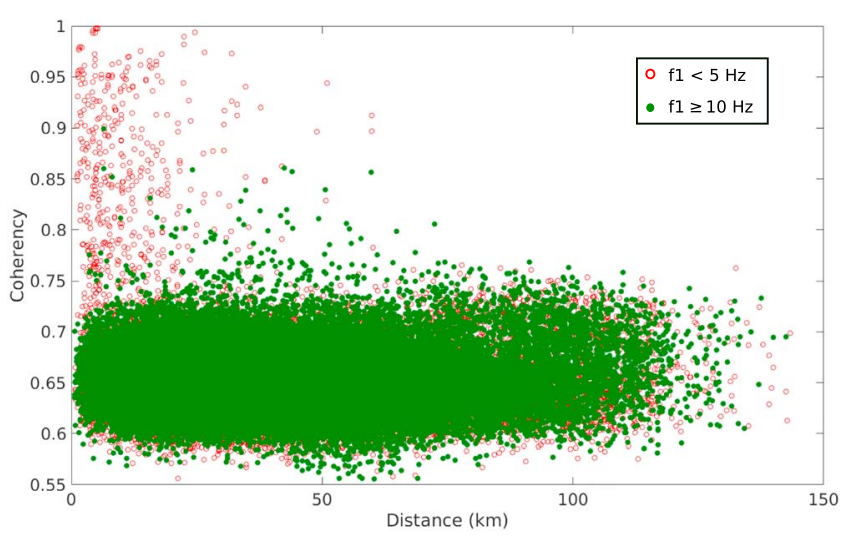

Figure 9. Coherency versus distance for every pair of templates used in this study. The hypocentral distances are calculated with the Japan Meteorological Agency locations. The red and green dots indicate the pairs of template that have their maximum coherency value at low and high frequencies, respectively. frequency.

Thus, we will consider a threshold of 0.8 thereafter with an uncertainty of 22.6 and $49 \mathrm{~km}$ for events detected at low and high frequencies, respectively.

\section{3. $P$ and $S$ Stacks}

To test if the signals detected at this threshold are really physical, we stack the continuous signal at the time of 30 detections obtained using one single template signal. The coherency between the projected and the template reference signals is comprised between 0.80 and 0.89 with a mean of 0.84 at high frequencies (between 14 and $20 \mathrm{~Hz}$ ). As already mentionned before, we know the time of detections with a precision of $5 \mathrm{~s}$. We computed the coherency between the template and the continuous signal between 1 and $20 \mathrm{~Hz}$. We align the signals at the time of the highest coherency value and stack all the continuous signals at every station and filter at low frequencies (between 0.7 and $3 \mathrm{~Hz}$ ) to keep the most coherent phase between the signals. An example is shown in Figure S4 for station 

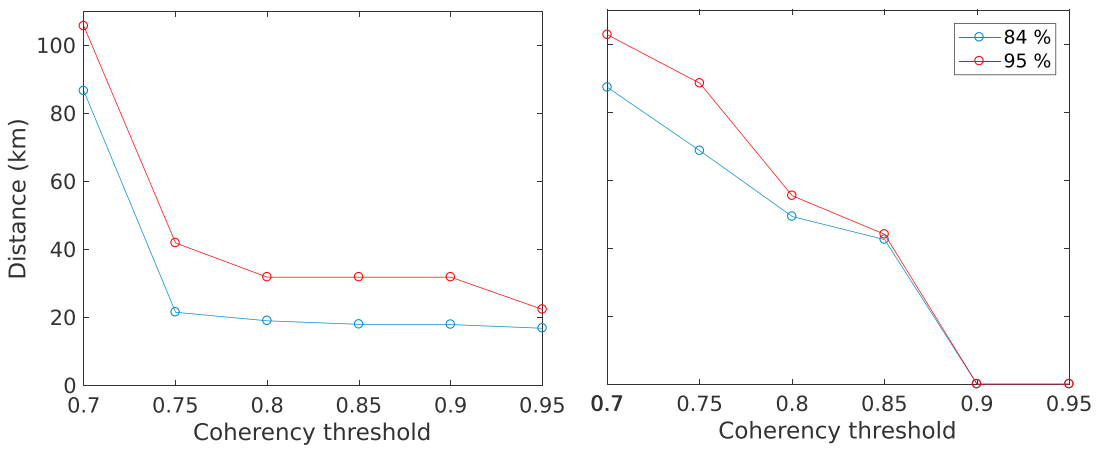

Figure 10. (left) Distance that contains $84 \%$ (in blue) or $95 \%$ (in red) of the pairs of template that have their maximum coherency value at low frequency. For example, $84 \%$ of the pairs of templates are located one to another at a maximum distance of $23 \mathrm{~km}$ for the 0.8 threshold. (right) Same for pairs of templates that have their maximum coherency value at high frequency.

N.KAKH. The stack displays a phase coherent with the template from 3 to $10 \mathrm{~s}$. This corresponds to the direct $P$ wave arrivals, reflections, single scattering, and a series of close arrivals. The signal between 10 and 20 s correspond to the $P$ coda waves.

Using the east component, we compute the coherency between the $S$ wave of the template and the continuous signal that follows the time of detection of the $P$ waves of Figure S4 (Figure 11). We stack at the time of maximum coherency. We retrieve both the $P$ and $S$ waves. The $P$ waves arrive at around $6 \mathrm{~s}$, and the $S$ wave are aligned at $26 \mathrm{~s}$; thus, the difference between the $S$ wave and the $P$ wave arrival times is $20 \mathrm{~s}$, although this difference is not very well constrained $( \pm 1 \mathrm{~s})$. The template that detected these earthquakes has a difference between the $S$ wave and the $P$ wave arrival times of $20 \mathrm{~s}$. This supports the location of the detected earthquakes inside the studied area.

As it is not possible to relocate these events using the time delay calculation, we hypothesize that they come from the surrounding of the template location (i.e., within 20 and $49 \mathrm{~km}$, the spatial resolutions of the method; Figure 10).
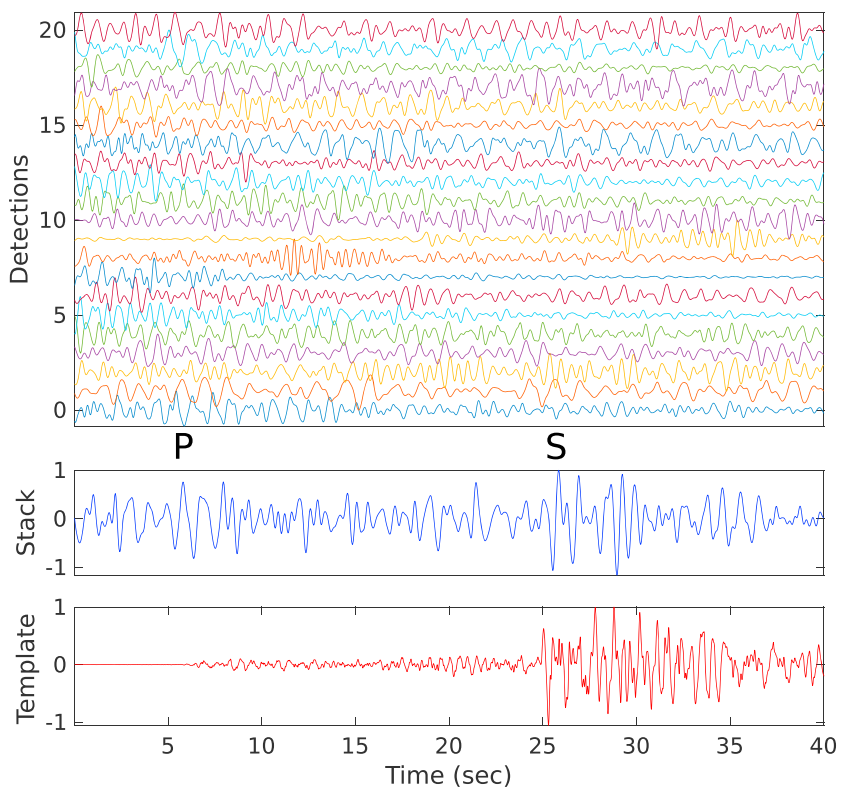

Figure 11. Example of a stack computed on the continuous signal at station N.KAKH. (top) Normalized waveforms recorded at N.KAKH, on the horizontal component (east) of the continuous signal at the time of detected earthquakes. (middle) Normalized stack of the waveforms. (bottom) Normalized waveform of the template used that occurred on 10 February 2011 at $23 \mathrm{hr} 50, M=5.2$.
As already mentioned, the events are detected either at low frequencies $(1 \leq f 1 \leq 5 \mathrm{~Hz})$ or at high frequencies $(f 1 \geq 10 \mathrm{~Hz})$. Examples of detection at low and high frequencies can be found in the supporting information (Figures S5 and S6). In the following, we study the two groups separately. In the next section, we present the results of the detection without taking into account the autodetections.

\subsection{Detections at Low Frequency}

The low-frequency detections present a rather constant seismic rate of 0.63 events per day until 16 February (Figure 12, in green). After this date, the seismic rate is multiplied by more than 4 until 26 February when it gets back to its previous rate. After the $M w 7.3$ foreschock, we observe a strong increase of the low-frequency detection rate.

We computed the probability density function of the time interval seperating two detections of a same template for different bin intervals (Figure 13, in green). A slope of -1 indicates clustering and short-term correlation between detected events that follows Omori's law. The events detected at low frequency (in green in Figure 13) appear to be clustered. Indeed, before the $M w 7.3$ foreshock, these events occurred during the migration that takes place from 16 February 2011 to 26 February 2011 evidenced by Kato et al. (2012). During the migration episode, the seismic rate is 4.3 times higher than the premigration and postmigration rates that are around 0.65 events per day (Figure 12). We projected the detected events on a line parallel to the trench that crosses the Tohoku earthquake epicenter (Figure 14). This allows to follow the migration in time and 


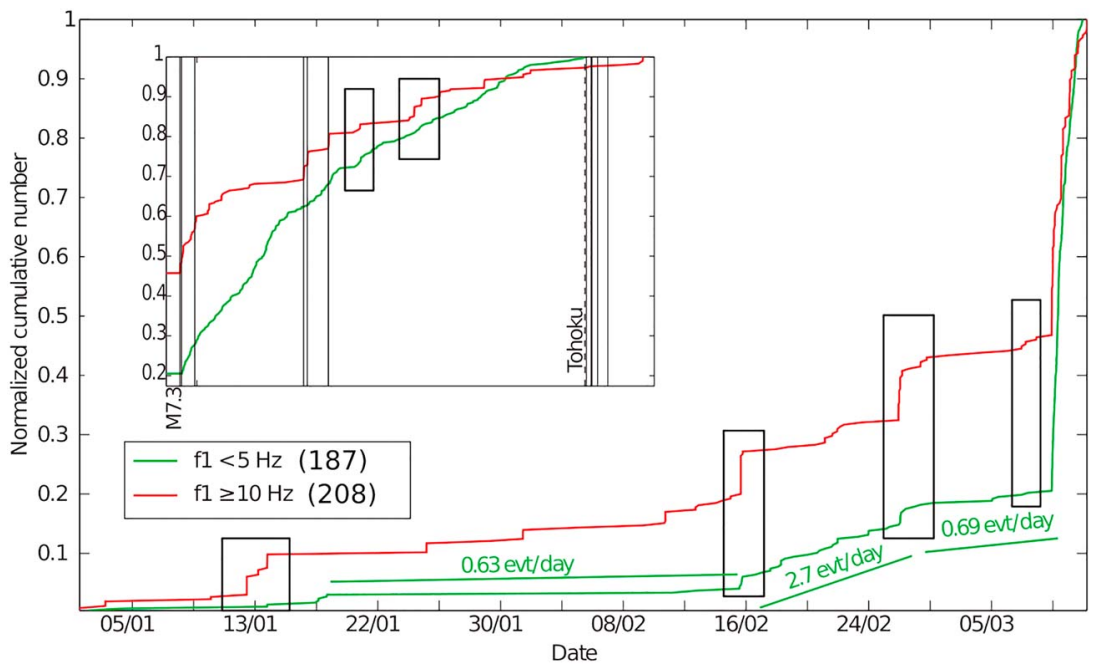

Figure 12. Normalized cumulative number of the newly detected events with time (without autodetections) separated into two groups: low-frequency detections (green) and high-frequency detections (red). Moreover, 45 detections have $5<f 1<10 \mathrm{~Hz}$ but are not shown here. Inset: zoom on the period after the Mw7.3 foreshock from the M7.3 to 12 March 2011. The vertical black lines indicate the time of occurrence of $M \geq 6$ earthquakes, and the dashed line indicates the Tohoku earthquake. The rectangles underline the time of occurrence of bursts of events detected at high frequency.

space (dashed line in Figure 14b). Apart from this migration, there is a small increase of seismic activity on 18 January 2011 due to a $M 4.1$ earthquake that occurred nearby.

A possible second migration episode might take place just before the $M w 7.3$ foreshock (dashed line in Figure 14a). However, only a few events (five) occurred. This episode appears to stop on 8 March 2011 and is followed by a quiescence that is ended by the $M w 7.3$ foreshock rupture.

After this earthquake, the events detected at low frequency present a constant rate showing a rather smooth behavior only slightly perturbed by the first burst on 10 March 2011. The second migration observed by Kato et al. (2012) is indicated and is also clearly seen by the low-frequency detections (dashed line in Figure 14a). The M6 earthquakes do not seem to affect the activity related to the events detected at low frequency.

\subsection{Detections at High Frequency}

The earthquakes detected at high frequency present a totally different dynamic. They occur during bursts of activity in between which the seismic rate presents the same trend as the seismic rate of the earthquakes

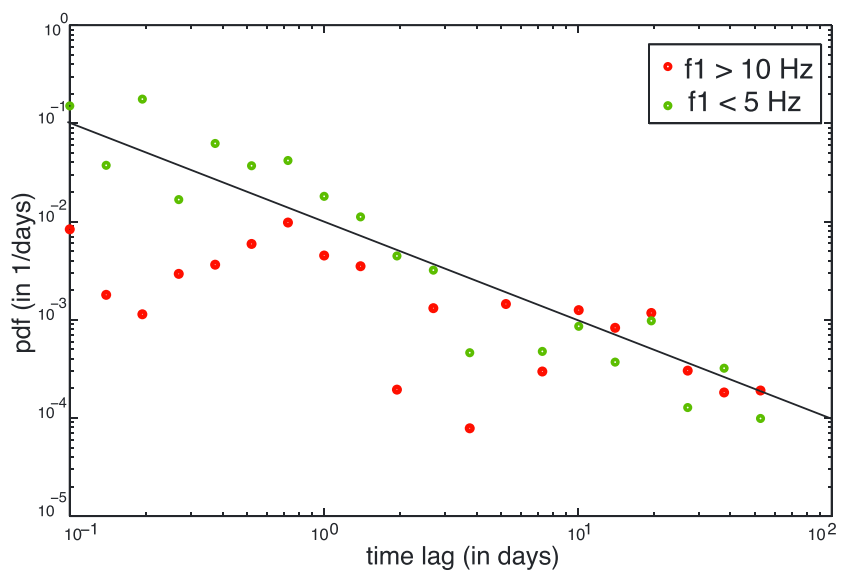

Figure 13. Probability density function (pdf) of the time intervals between two detections of the same template for low-frequency detections (in green) and high-frequency detections (in red). The black line indicates a slope of -1 . detected at low frequency (Figure 12, in red).

Other bursts of activity take place between the $M w 7.3$ foreshock and the Tohoku-Oki earthquake. These are mostly due to $M \geq 5$ earthquakes that occurred after the foreshock. The small number of detections after the megathrust rupture suggests that coseismic slip was relatively uniform in the area and that the stress drop was important, which is consistent with the lack of aftershocks there (Lengliné et al., 2012).

The slope of the pdf in log-log scale is close to -1 with a flat first regime for time intervals inferior to 1 day (Figure 13, in red). This suggests that the process driving these earthquakes is less clustered than for the low-frequency detections but still non-Poissonian. We computed the projection on the same line as we did for the earthquakes detected at low frequency and see that each burst extends over the entire zone from 15 to $70 \mathrm{~km}$ (Figure 15). The spatial distribution of earthquakes detected at high frequency is much less homogeneous than for events detected at low frequency since they are detected by M4.8 to M6.8 earthquakes. They are indicated by the red areas in Figure 15. 


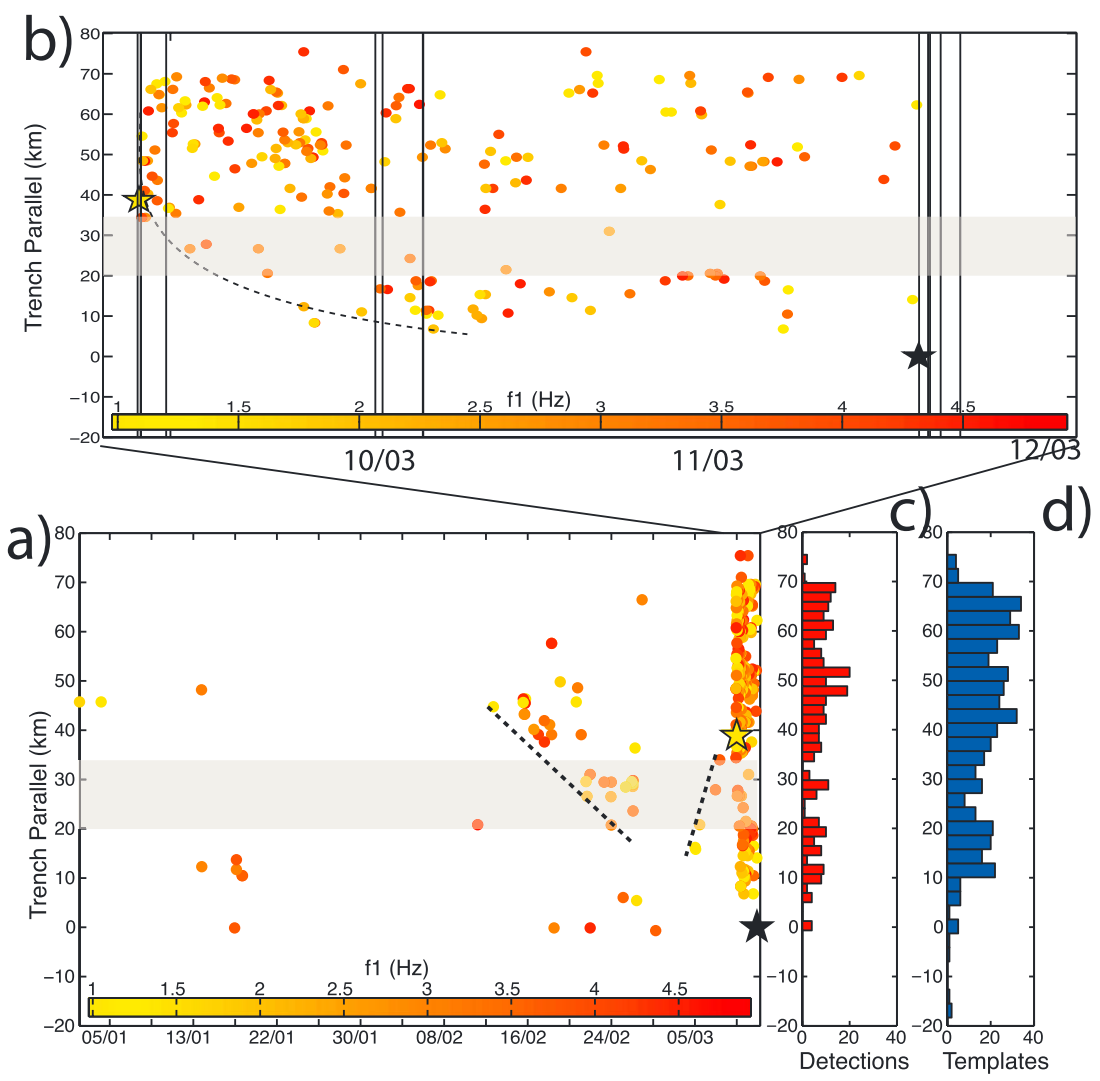

Figure 14. Space-time diagram of events detected at low frequencies without the autodetections, the locations correspond to the template locations. (a) Space-time distribution of event detected at low frequencies. The color code gives f1 (Hz). The earthquakes are located according to their distance along a line parallel to the trench axis. The yellow and black stars indicate the time of occurrence of the $M w 7.3$ foreshock and the Tohoku-Oki earthquake, respectively. The first migration indentified by Kato et al. (2012) is indicated with a dashed line. The gray band characterizes a weakly active zone located in Figures 17 and 18. (b) Zoom on the space-time diagram between the $M w 7.3$ foreshock and 12 March 2011. The vertical black lines indicate the time of occurrence of $M \geq 6$ earthquakes. The second migration identified by Kato et al. (2012) is indicated with a dashed line. (c) Number of detections along the trench parallel line. (d) Number of templates along the trench parallel line.

Detections following the $M 4.8$ to $M 6$ earthquakes are spread over all the area, every time an $M \geq 6$ earthquake occurs (Figure 15). There are also few bursts after the $M w 7.3$ foreshock that are not due to $M 6$ activity. The main burst occurred on 10 March 2011, lasted $1.5 \mathrm{hr}$ (from 4.26 to 6 p.m.) and contained 16 new earthquakes and is concomittent with a magnitude 4.6 earthquake followed by a magnitude 5.9.

Since the high-frequency earthquakes are mainly detected with the M4.8 to M6.8 templates, we ran the MDTM over year 2010 for the six templates that correspond to the six red areas in Figure 15, to check whether or not the seismic activity did start on 13 Janurary 2011. In fact, it appears that a burst occurred on 30 November 2010 so 5 months before the mainshock. After this burst, there is an increase of high-frequency detections until the Tohoku earthquake (Figure 16). The largest earthquakes at depth $(z>80 \mathrm{~km})$ between July and December 2010 occurred on 24 November 2010 (M4.1) and on 31 December 2010 (M3.5). At shallow $(z \leq 40 \mathrm{~km})$ depth, the largest event that occurred in the epicentral area during the entire year of 2010 is on 10 December 2011 (M3.8), followed in early 2011 by 6 January 2011 (M3.6). This is consistent with an activation of the seismicity on November 2010 and with the gravity variations derived from GRACE stallite data that started from late 2010 (Panet et al., 2018).

We hypothesize that they are slip markers which imply that their number is proportionnal to the cumulative slip. In fact, considering that the $M w 7.3$ foreshock triggered around $35 \mathrm{~cm}$ of postseismic slip (Ohta et al., 2012), we can see that 133 earthquakes detected at high frequency were triggered in the meantime which gives a slip rate per event of around $0.26 \mathrm{~cm}$ per event. 


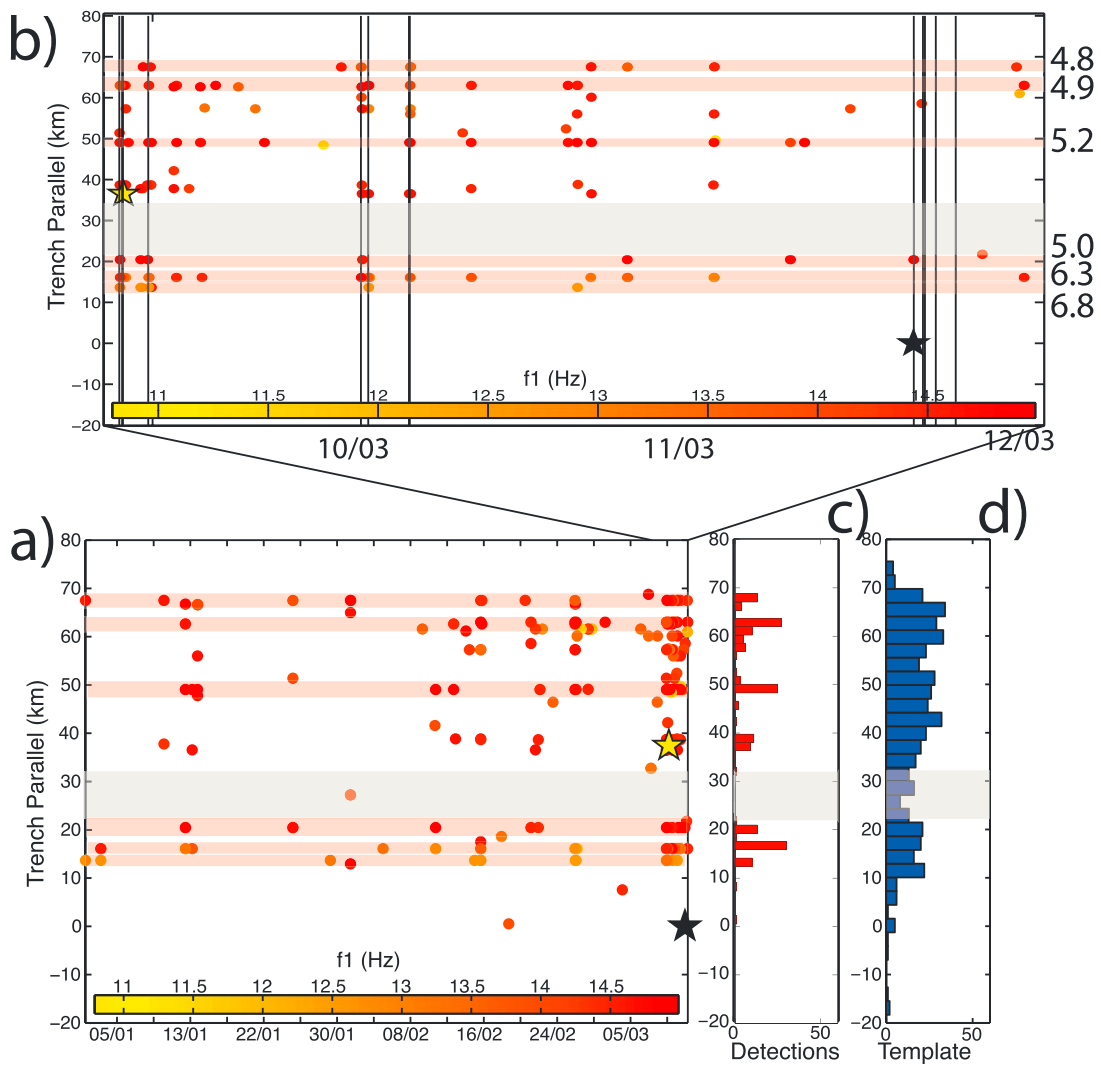

Figure 15. Same as Figure 14 for events detected at high frequencies, without the autodetections. The red areas locate the zones where high-frequency detected earthquakes are activated several times and that correspond to the location of M4.8 to M6.8 templates. They are located on or near the rupture zone of large earthquakes. The magnitudes of these earthquakes is given in (b). The vertical black lines indicate the time of occurrence of $M \geq 6$ earthquakes.

Between January and November 2010, 62 earthquakes occurred including 45 in the area of maximum postseismic slip located between the Mw7.3 foreshock and the Tohoku epicenters. This would suggest that $11.7 \mathrm{~cm}$ of slip occurred in the surrounding area. This reasoning would yield an annual slip of $12.72 \mathrm{~cm} / \mathrm{year}$ which is more than the loading rate of $8.3 \mathrm{~cm} /$ year. This computation holds if the considered areas are the

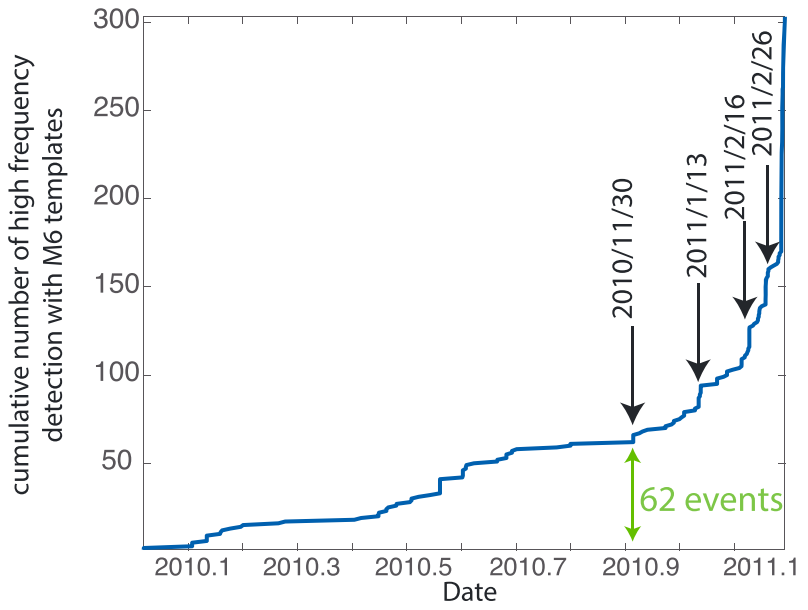

Figure 16. Cumulative number of earthquakes for the high frequency detections from 1 January 2010 to March 2011 using the six M4.8 to M6 templates only. same. This simple reasoning supposes that the velocity of $12.72 \mathrm{~cm} /$ year is local. It might be overestimated, but it suggests that the area was not fully coupled during the year 2010 .

We note that repeating earthquakes have been identified in this zone prior to the Tohoku earthquake by Uchida and Matsuzawa (Uchida \& Matsuzawa, 2013) which led these authors to estimate a preseismic slip rate in the 2- to $3-\mathrm{cm} /$ year range for a wider $37.5-39^{\circ} \mathrm{N}$ area, based on the assumption that the Nadeau and Johnson relationship developed for California (Nadeau \& Johnson, 1998) works also for Japan.

With the MDTM algorithm, we detect earthquakes at both low and high frequencies that did not follow the same dynamic during the preparatory phase of the Tohoku earthquake even if they are located in the rupture area of the megathrust event. This implies that two situations occur that show two different behaviors: a relatively smooth distribution in time and space using $M 2$ to $M 3$ templates (events detected at low frequency) versus the M4.8 to M6 templates that detect at high-frequency earthquakes that occur as bursts and that are spatially correlated. However, a common feature to both earthquakes detected at low and high frequency 
distributions in the space-time diagram is the presence of a weakly active band between 21 and $34 \mathrm{~km}$ (gray band in Figures 14 and 15).

Note that the detections we obtain with the method are dependent on the template locations. It allows to capture the dynamics of the zones where templates are. Here, we thus observe the behavior in the large earthquake rupture zones at $\pm 20 \mathrm{~km}$ from their epicenters, given the resolution of our method, but it is not excluded that other earthquakes occurred on the subducting slab. Note the presence of $M 2$ to M3 templates earthquakes in this zone.

Next section presents the history of the seismicity in the area before the megathrust event.

\section{Discussion}

4.1. Detailed Seismic History in the Tohoku Rupture Zone

Three major earthquakes struck the Tohoku-Oki rupture area from the 1920s to 2003: in 1958 (M6.7), 1978 (M7.4), and the M7.0 1981 earthquake (Sato et al., 2013).

Their rupture zone is located in areas surrounding the large slip patch of the Tohoku earthquake except for the 1981 event which slip area is located in a region of relatively slow slip of the Tohoku earthquake (Hasegawa \& Yoshida, 2015; Yamanaka \& Kikuchi, 2004). This suggests that the area that presents high coseismic slip during the Tohoku earthquake was locked throughout this period, whereas the stress was at least partially released in the surrounding zones. The seismic activity began to increase after 2003 when several $M 7$ earthquakes occurred. During this period, the seismic coupling was not constant in the eastern Japanese subduction zone (Marsan et al., 2017). Indeed, inland GPS time series show changes in rate between 1998 and 2011 in the northern Tohoku, where they evidence an increase in slip deficit rate, and in south central Tohoku, where they show a decrease of slip deficit rate (Mavrommatis et al., 2014; Yokota \& Koketsu, 2015).

Postseismic slip of large earthquakes, in particular the 1994 Mw7.6 Sanriku and the 2003 Mw8.1 Tokaichi earthquakes, that occurred in the northern zone can explain such increases in slip deficit rate; however, no postseismic effects can explain the decrease in the south. This suggests that a long-term aseismic slip of about 10-year duration preceded the Tohoku earthquake. Smaller slow-slip transients were evidenced using ocean bottom pressure gauges (Ito et al., 2013). Their analysis indicates that a slow-slip transient occurred on the plate interface in 2008 with a duration of a week and a moment magnitude of 6.8 .

At the end of 2010, the seismic rate of the earthquakes detected at high frequency increases after a burst-like episode on 30 November. The beginning of the preseismic phase at the end of 2010 is consistent with the seismic activity at shallow and greater depths. The future rupture zones of the M4.8 to M6.8 earthquakes or their surroundings are thus active from January 2010, and the seismic activity increases from November 2010 to the date of their ruptures.

In mid-January, the deep seismicity increases (Bouchon et al., 2016), accompanied by a seismic burst at shallower depth (Figure 17a). During this period, the earthquakes were mainly detected at high frequency and occurred in three of the high-frequency patches identified in Figure 17 by gray diamonds. After this burst, only earthquakes detected at high frequencies occurred, mainly on the same patches. The fact that these patches regularly break and that there is no activity in the gray band indicated in Figures 14 and 15 strongly suggests the presence of an aseismic zone nearby (area delimited by the dashed line in Figure 17).

The northern high-frequency patches are located close to the sources of five Very Low Frequency Earthquakes (VLFEs) that occurred in 2007, 2009, and 2011 (Matsuzawa et al., 2015). The presence of VLFEs could be linked to the existence of a fluid layer in this area resulting in a high intensity in seismic reflection (Fujie et al., 2002). These evidences point to a weakly coupled interface area. This is confirmed by the occurrence of a slow-slip event (SSE) that occurred 1 month before the Tohoku earthquake accompanied by seismic activity and that reactivated the 2008 SSE patch (Ito et al., 2013; Figures 17d-17f), although the spatial extent of this SSE patch is badly resolved. Note that no VLFEs were found in the aseismic zone delimited in Figure 17.

Our observations confirm the migration episode of earthquakes from 13 February 2011 to 26 February 2011 (Figures 17d-17f). The activity begins with a burst of earthquakes detected at high frequency which is followed by a maintained activity of earthquakes detected at low frequency mainly located close to the $M w 7.3$ 

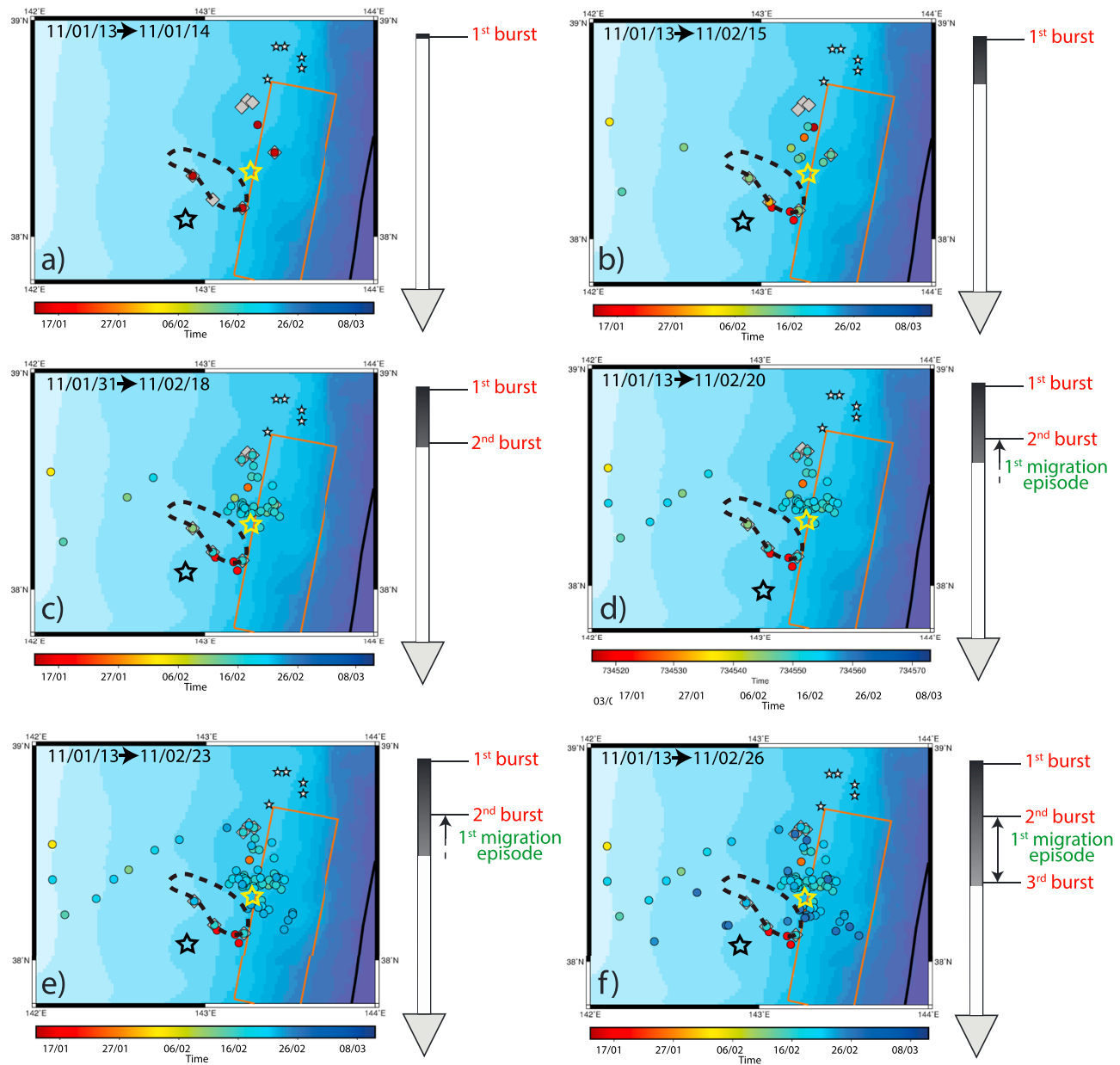

Figure 17. Snapshots of the seismicity in the studied area. The slipping patch of the 2011 SSE is shown in orange (Ito et al., 2013). The epicenters of the $M w 7.3$ foreshock and the Tohoku-Oki earthquake are shown in yellow and black, respectively. White stars indicate the locations of VLFEs (Matsuzawa et al., 2015). The dashed line indicates the aseismic slip zone. The events are color coded according to their time of occurrence. Gray diamonds identify the high-frequency patches. The gray arrow on the right indicates the occurrence time of bursts and migration episodes.

foreshock epicenter, first to the north and then migrating to the south. This migration is only seen for the earthquakes detected at low frequency and occurs during the SSE. This sequence of earthquakes ended with a burst of high-frequency detections on 26 February 2011. No events detected at low frequency occurred after this migrating sequence until another seismic activity increase from 5 March 2011 to 7 March 2011 that took place in the downdip part of the studied area (Figure 18a).

Following this highly active period, the entire area experienced a quiescence that lasted $25 \mathrm{hr}$. We tested if this quiescence is an unusual feature during the period of study by calculating the number of events during periods of $25 \mathrm{hr}$ chosen randomly from 1 January 2011 to 6 March 2011. It appears not unusual to have an absence of seismicity during such a duration. However, it is surprising that after such an intense seismic phase, nothing should happen before the $M w 7.3$ foreshock.

The loading of the area surrounding the $M w 7.3$ rupture zone by the SSE and recurrent transient slips in the aseismic zone resulted in increasing the stress state on the $M w 7.3$ asperity that eventually breaks after a quiescence of 1 day. The Mw7.3 foreshock occurred on 9 March 2011 and mainly triggered aftershocks north of the epicenter. The postseismic slip is partly located in the southwest area between the epicenters of the foreshock and the Tohoku earthquake (Ohta et al., 2012, and Figure 3) confirming the presence of an aseismic zone in this location.

After its rupture, the main foreshock triggered both aseismic slip and aftershocks seen with seismicity (Marsan \& Enescu, 2012) and ocean-bottom pressure records (Hino et al., 2014). There was a second 

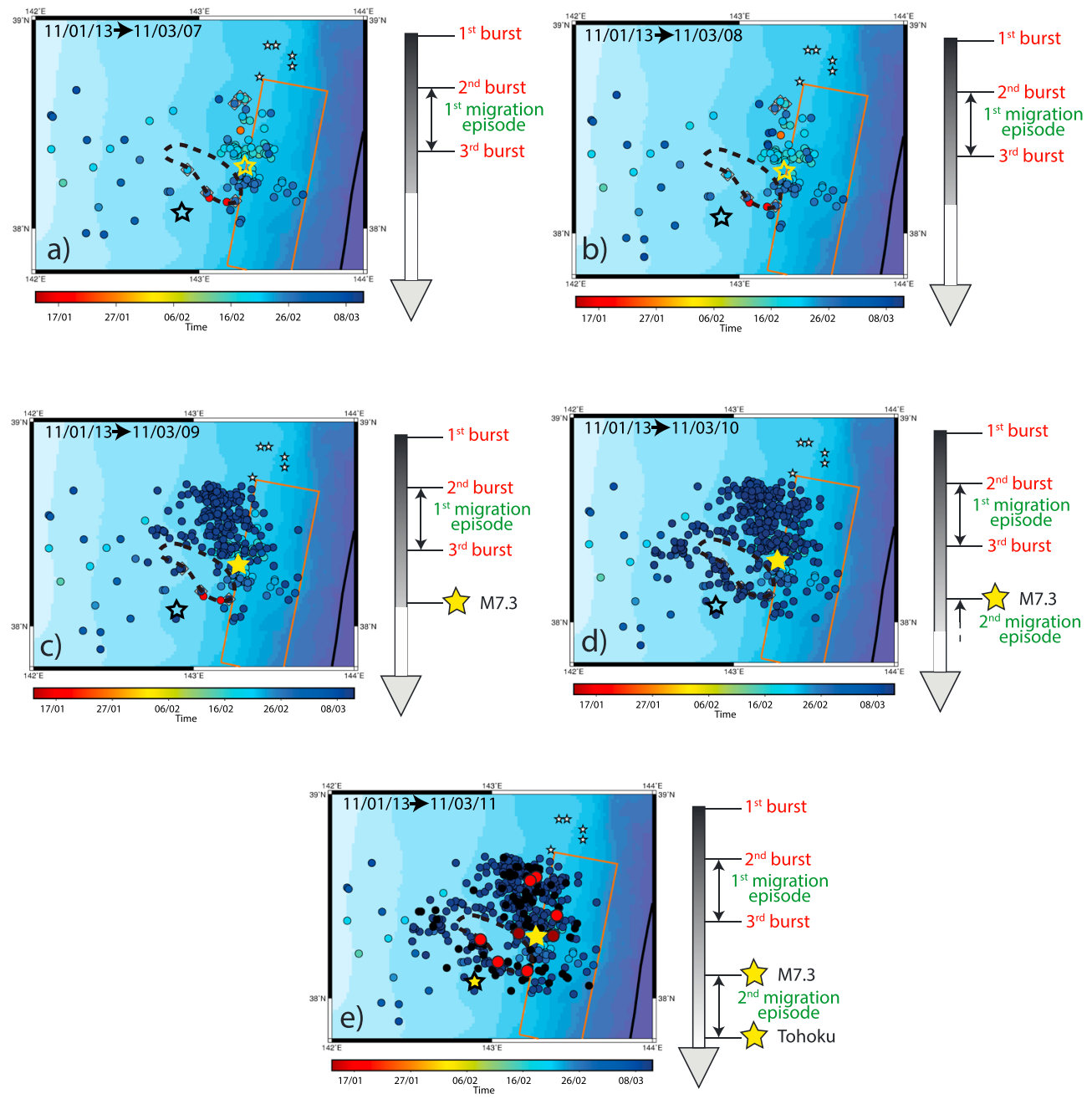

Figure 18. Same as Figure 17. On (e) the red dots indicate the position of $M \geq 4.8$ earthquakes, and the brown dots correspond to the templates that detected most of the high-frequency events accounting for the detections from 1 January 2010 to 11 March 2011.

migration episode to the southwest that started only $7 \mathrm{hr}$ after the foreshock (Figure 18d). This migration along with the aseismic slip loaded the southwest side of the aseismic slip leading to three $M 6$ aftershocks that occurred 16 and $18 \mathrm{hr}$ after the $M w 7.3$ foreshock, on the patches of events detected at high frequency. The rupture zone of the M4.8 to M6.8 earthquakes and surroundings located south to the aseismic patch was particularly active before the Tohoku earthquake (in brown in Figure 18f). These large events produced their own aftershocks and thus provoked a cascade of ruptures close to the Tohoku earthquake asperity. Eventually, the Tohoku earthquake struck the area triggering numerous aftershocks out of the studied zone.

\section{Conclusion}

Using the MDTM algorithm, we detect 395 new earthquakes from 1 January 2011 to 12 March 2011 that can be separated into two groups: earthquakes detected at low frequency, mainly with small (M2 to $M 3)$ templates and events detected at high frequency, mainly with larger (M4.8 to M6.8) earthquake records.

These two groups follow different behaviors with time.

- The earthquakes detected at low frequency evidence the two migration episodes that occurred both before and after the $M w 7.3$ foreshock and do not present activity before the $M w 7.3$ apart from the migration.

- On the contrary, the earthquakes detected at high frequency that are occurring in zones prone to large earthquakes as bursts and extend over the entire area. Using the M4.8 to M6.8 templates of the most active 
areas, we see that the events detected at high frequency are active during the entire year 2010 and that their seismic rate increases from November 2010 to 12 March 2011. The area seems to be only partly coupled before the Tohoku earthquake. These events are located on the rupture area of the $M 4.8$ to M6.8 earthquakes (especially south to the aseismic zone) that occurred before the Tohoku earthquake. These rupture zones were thus highly active during the entire preseismic phase, especially during burst-like episodes that affected the entire area, likely triggered by aseismic slip. This aseismic slip is located north to the M6 rupture zones and interacted with the seismic migration episode since bursts of events detected at high frequency occurred both at the beginning and at the end of the SSE.

We thus evidence deformation episodes of different duration on a wide zone alternating with seismicity before the Tohoku earthquake. This type of dynamic is not always present before large earthquakes (Johnston et al., 2006). The MDTM algorithm could be combined with a denoising preprocessing of the continuous data thus enhancing even more the signal-to-noise ratio. The application of the MDTM technique on such earthquakes could bring more insights on the phase before the mainshock, especially to detected events at high frequency.

\section{Acknowledgments}

Earthquake data were kindly provided by the Japan Meteorological Agency in cooperation with the Ministry of Education, Culture, Sports, Science, and Technology. We acknowledge the help of the National Research Institute for Earth Science and Disaster Prevention, Tsukuba (http://www. hinet.bosai.go.jp/), for making available their waveform data through their website. Most of the computations presented in this paper were performed using the CIMENT infrastructure (https://ciment. ujf-grenoble.fr), which is supported by the Rhône-Alpes region (Grant CPER07_13 CIRA: http://www.ci-ra. org) and France-Grille (http://www. france-grilles.fr). Many thanks to B. Bzeznik and F. Roch. We acknowledge support from the European Research Council under the European Union Horizon 2020 research and innovation program (grant agreement 742335 , F-IMAGE). We are deeply thankful for the reflections and debates shared with Raùl Madariaga, Aitaro Kato, Alexandre Schubnel, Anthony Sladen, and Olivier Lengliné. We acknowledge the help of two anonymous reviewers who greatly helped to improve the manuscript.

\section{References}

Ando, R., \& Imanishi, K. (2011). Possibility of Mw 9.0 mainshock triggered by diffusional propagation of after-slip from Mw 7.3 foreshock. Earth, Planets and Space, 63(47), 767-771.

Aso, N., Ohta, K., \& Ide, S. (2011). Volcanic-like low-frequency earthquakes beneath Osaka Bay in the absence of a volcano. Geophysical Research Letters, 38, L08303. https://doi.org/10.1029/2011GL046935

Bienvenu, G., \& Kopp, L. (1983). Optimality of high resolution array processing using the eigen system approach. Institute of Electrical and Electronics Engineers, 31(5), 1235-1248.

Bouchon, M., Karabulut, H., Aktar, M., Ozalaybey, S., Schmittbuhl, J., \& Bouin, M. (2011). Extended nucleation of the 1999 Mw 7.6 Izmit earthquake. Science, $331,877$.

Bouchon, M., Marsan, D., Durand, V., Campillo, M., Perfettini, H., Madariaga, R., \& Gardonio, B. (2016). Potential slab deformation and plunge prior to the Tohoku, Iquique and Maule earthquakes. Nature Geoscience, 9, 380-383. https://doi.org/10.1038/NGEO2701

Delbridge, B. G., Kita, S., Uchida, N., Johnson, C. W., Matsuzawa, T., \& Bürgmann, R. (2017). Temporal variation of intermediate-depth earthquakes around the time of the M9.0 Tohoku-Oki earthquake. Geophysical Research Letters, 44, 3580-3590. https://doi.org/10.1002/ 2017GL072876

Fujie, G., Kasahara, J., Hino, R., Sato, T., Shinohara, M., \& Suyehiro, K. (2002). A significant relation between seismic activities and reflection intensities in the Japan Trench region. Geophysical Research Letters, 29(7), 1100. https://doi.org/10.1029/2001GL013764

Gibbons, S., \& Ringdal, F. (2006). The detection of low magnitude seismic events using array-based waveform correlation. Geophysical Journal International, 165, 149-166.

Glangeaud, F., \& Lacoume, J. (1985). Corrections of seismic traces by adaptive signal processing. Applied Signal Processing, $263-266$.

Glangeaud, F., \& Latombe, C. (1986). Multicomponent filtering of magnetic signals. Signal Processing, 11(2), 133-143.

Got, J., Fréchet, J., \& Klein, F. (1994). Deep fault plane geometry inferred from multiplet relative relocation beneath the south flank of Kilauea. Journal of Geophysical Research, 99, 15,375-15,386.

Hasegawa, A., \& Yoshida, K. (2015). Preceding seismic activity and slow slip events in the source area of the $2011 \mathrm{Mw} 9.0 \mathrm{Tohoku}-\mathrm{Oki}$ earthquake: A review. Geoscience Letters, 2, 6. https://doi.org/10.1186/s40562-015-0025-0

Hino, R., Inazu, D., Ohta, Y., Ito, Y., Suzuki, S., Iinuma, T., et al. (2014). Was the 2011 Tohoku-Oki earthquake preceded by aseismic preslip? examination of seafloor vertical deformation data near the epicenter. Marine Geophysical Research, 35, 181-190.

Hirose, F., Miyaoka, K., Hayashimoto, N., Yamazaki, T., \& Nakamura, M. (2011). Outline of the 2011 off the Pacific coast of Tohoku earthquake (Mw 9.0)-Seismicity: Foreshocks, mainshock, aftershocks, and induced activity-. Earth, Planets and Space, 63(1), 513-518.

Ito, Y., Hinoa, R., Kidob, M., Fujimotob, H., Osadab, Y., Inazuc, D., et al. (2013). Episodic slow slip events in the Japan subduction zone before the 2011 Tohoku-Oki earthquake. Tectonophysics, 600, 14-26.

Jensen, F., Kuperman, W. A., Porter, M., \& Schmidt, H. (2011). Computational ocean acoustic (2nd ed.). Berlin: Springer-Verlag.

Johnston, M., Borcherdt, R., Linde, A., \& Gladwin, M. (2006). Continuous borehole strain and pore pressure in the near field of the 28 September 2004 M6.0 Parkfield, California, earthquake: Implications for nucleation, fault response, earthquake prediction, and tremor. Bulletin of the Seismological Society of America, 96(4B), S56-S72.

Kato, A., Obara, K., Igarashi, T., Tsuruoka, T., Nakagawa, S., \& Hirata, N. (2012). Propagation of slow slip leading up to the 2011 Mw 9.0 Tohoku-Oki earthquake. Science, 335, 705-708.

Kimura, H., Kasahara, K., Igarashi, T., \& Hirata, N. (2006). Repeating earthquake activities associated with the Philippine Sea plate subduction in the Kanto district, central Japan: A new plate configuration revealed by interplate aseismic slips. Tectonophysics, 417, 101-118.

Lengliné, O., Enescu, B., Peng, Z., \& Shiomi, K. (2012). Decay and expansion of the early aftershock activity following the 2011, Mw9.0 Tohoku earthquake. Geophysical Research Letters, 39, L18309. https://doi.org/10.1029/2012GL052797

Lengliné, O., \& Marsan, D. (2009). Inferring the coseismic and postseismic stress changes caused by the $2004 \mathrm{Mw}=6 \mathrm{Parkfield}$ earthquake from variations of recurrence times of microearthquakes. Journal of Geophysical Research, 114, B10303. https://doi.org/10. 1029/2008JB006118

Marsan, D., Bouchon, M., Gardonio, B., Perfettini, H., Socquet, A., \& Enescu, B. (2017). Change in seismicity along the Japan trench, 1990-2011, and its relationship with seismic coupling. Journal of Geophysical Research: Solid Earth, 122, 4645-4659. https://doi.org/10. 1002/2016JB013715

Marsan, D., \& Enescu, B. (2012). Modeling the foreshock sequence prior to the 2011, Mw9.0 Tohoku, Japan, earthquake. Journal of Geophysical Research, 117, B06316. https://doi.org/10.1029/2011JB009039

Matsuzawa, T., Asano, Y., \& Obara, K. (2015). Very low frequency earthquakes off the Pacific coast of Tohoku, Japan. Geophysical Research Letters, 42, 4318-4325. https://doi.org/10.1002/2015GL063959 
Matsuzawa, T., Igarashi, T., \& Hasegawa, A. (2002). Characteristic small-earthquake sequence off Sanriku, northeastern Honshu, Japan. Geophysical Research Letters, 29(11), 1543. https://doi.org/10.1029/2001GL014632

Mavrommatis, A., Segall, P., \& Johnson, K. M. (2014). A decadal-scale deformation transient prior to the $2011 \mathrm{Mw} 9.0 \mathrm{Tohoku}-\mathrm{Oki}$ earthquake. Geophysical Research Letters, 41, 4486-4494. https://doi.org/10.1002/2014GL060139

Mermoz, H. (1976). Imagerie, corrélation et modèles. Annales Des Telecommunications, 31, 17-36.

Nadeau, R., \& Johnson, L. (1998). Seismological studies ar Parkflied VI: Moment release rates and estimates of source parameters for small repeating earthquakes. Bulletin of the Seismological Society of America, 88(3), 790-814.

Nadeau, R. M., \& McEvilly, T. V. (1997). Seismological studies at Parkfield V: Characteristic microearthquake sequences as fault-zone drilling targets. Bulletin of the Seismological Society of America, 87(6), 1463-1472.

Ohta, Y., Hino, R., Inazu, D., Ohzono, M., Ito, Y., Mishina, M., et al. (2012). Geodetic constraints on afterslip characteristics following the March 9, 2011, Sanriku-Oki earthquake, Japan. Geophysical Research Letters, 39, L16304. https://doi.org/10.1029/2012GL052430

Panet, I., Bonvalot, S., Narteau, C., Remy, D., \& Lemoine, J.-M. (2018). Migrating pattern of deformation prior to the Tohoku-Oki earthquake revealed by grace data. Nature Geoscience, 11(5), 367.

Peng, Z., \& Zhao, P. (2009). Migration of early aftershocks following the 2004 Parkfield earthquake. Nature Geoscience, 2 , 877-881.

Perfettini, H., \& Avouac, J. (2014). The seismic cycle in the area of the 2011 Mw9.0 Tohoku-Oki earthquake. Journal of Geophysical Research: Solid Earth, 119, 4469-4515. https://doi.org/10.1002/2013JB010697

Rost, S., \& Thomas, C. (2002). Array seismology: Methods and applications. Reviews of Geophysics, 40(3), 1008. https://doi.org/10.1029/ 2000RG000100

Samson, J. (1983). The spectral matrix, eigenvalues, and principal components in the analysis of multichannel geophysical data. Annales Geophysicae, 1(1), 115-125.

Sato, T., Hiratsuka, S., \& Mori, J. (2013). Precursory seismic activity surrounding the high-slip patches of the $2011 \mathrm{Mw} 9.0 \mathrm{Tohoku}-\mathrm{Oki}$ earthquake. Bulletin of the Seismological Society of America, 103(6), 3104-3114.

Shelly, D., Beroza, G., \& Ide, S. (2007). Non-volcanic tremor and low-frequency earthquake swarms. Nature, 446, 305-307.

Shelly, D. R., Ellsworth, W. L., \& Hill, D. P. (2016). Fluid-faulting evolution in high definition: Connecting fault structure and frequency-magnitude variations during the 2014 long Valley Caldera, California, earthquake swarm. Journal of Geophysical Research: Solid Earth, 121, 1776-1795. https://doi.org/10.1002/2015JB012719

Turek, G., \& Kuperman, W. (1997). Applications of matched-field processing to structural vibration problems. The Journal of the Acoustical Society of America, 101(3), 1430-1440.

Uchida, N., \& Matsuzawa, T. (2013). Pre- and postseismic slow slip surrounding the 2011 Tohoku-Oki earthquake rupture. Earth and Planetary Science Letters, 374, 81-91.

Uchida, N., Matsuzawa, T., \& Hasegawa, A. (2003). Interplate quasi-static slip off Sanriku, NE Japan, estimated from repeating earthquakes Geophysical Research Letters, 30(15), 1801. https://doi.org/10.1029/2003GL017452

Yamanaka, Y., \& Kikuchi, M. (2004). Asperity map along the subduction zones in NE Japan inferred from regional seismic data. Journal of Geophysical Research, 109, B07307. https://doi.org/10.1029/2003JB002683

Yokota, Y., \& Koketsu, K. (2015). A very long-term transient event preceding the 2011 Tohoku earthquake. Nature Communications, 6, 5934

Zhang, M., \& Wen, L. (2015). An effective method for small event detection: Match and locate (m\&l). Geophysical Journal International, 200(3), 1523-1537. 